\begin{tabular}{c} 
International Journal of Engineering \& Technology, $7(2.7)(2018) 219-224$ \\
International Journal of Engineering \& Technology \\
WPC \\
Website: www.sciencepubco.com/index.php/IJET \\
Research Paper \\
\hline
\end{tabular}

\title{
Design and implementation of weather fore casting system based on cloud computing and data mining techniques
}

\author{
Rajarajeswari. P $^{1}$ *, J. Pradeep kumar ${ }^{2}$, D. Vasumathi ${ }^{3}$ \\ ${ }^{1}$ Associate professor, Department of Computer science and Engineering Aditya college of Engineering, Madanapalle,Chitoor (Dt) \\ ,Andhra pradesh, India \\ ${ }^{2}$ Assistant Professor, Department of Computer science and Engineering Aditya college of Engineering,Madanapalle,Chitoor(Dt),An- \\ dhra Pradesh, India \\ ${ }^{3}$ Professor,Department of Computer science and Engineering Jntu,Hyderabad,Telegana \\ *Corresponding authorE-mail: rajacse77@gmail.com
}

\begin{abstract}
Software engineering is an engineering discipline which is used to analyze, modeling and development of the system. Normally Weather conditions are changing continuously with respective to atmospheric conditions. In the phase of modeling of the Weather fore casting system is performed by taking the data which is collected on atmospheric conditions and record temperature, rainfall, humidity and other parameters. The main objective of this paper is focused on Design and implementation of Weather forecasting system. Weather forecasting model is prepared by using Cloud computing and Data mining techniques. This System is analyzed by using temperature, rainfall conditions Statistical framework is provided on Modeling for surface process of weather forecasting with Data assimilation. This paper presents the Conceptual level architecture of Weather prediction model by using decision tree. Proposed algorithm is used for the construction of decision tree. Weather forecasting report is implemented by using Android.
\end{abstract}

Keywords: Weather Forecasting; Cloud Computing; Data Assimilation; Atmospheric Conditions.

\section{Introduction}

Weather forecasting is considered as one of the meteorological and challenging issue in the world. Number of Scientists has been focusing on characteristics of weather system by using various methods. Normally Weather prediction model is performed by using mathematical equations with the description of atmospheric temperature, pressure and moisture with respective to time [1]. Weather conditions are obtained by considering ground, ship, aircraft observations. Modern computers transfer the observations onto surface and map the lines from meteorologists for correcting the errors. The forecaster analyzes each model and does the predictions on best aspects of Weather forecasting model. It can be performed for 12 to 24 hours. Here Data mining techniques are used for analyzing the Weather prediction model. In this section 3 modeling for surface process of Weather forecasting is presented. Statistical framework for data assimilation is described in section 4. Cloud computing techniques are applied for Weather forecasting system in section 5. Data mining techniques for weather forecasting system is presented in section 6. Proposed algorithm and their results is presented in section 7.Different constraints are given for the construction of decision tree is given section 8.Conceptual level of architecture for Weather forecasting system is given in section 9. Design pattern for Weather forecasting system is provided in section 10. Implementation of weather forecasting report by using android and Conclusions are given in section 11 and 12 .

\section{Related work}

In this section we discuss some important aspects which are related to modeling of weather forecasting system.

\subsection{Climate changes}

Climate data gives the official data record that is provided after performing quality control activities. Synoptic data is considered as real-time data provided for doing forecast modeling. So many risks are produced to human society due to Climate changes.

\subsection{Weather forecasting}

It is a vital application in meteorology and facing problems in the world. Chen and Dudia have focused on hydrology model with coupling process of an advanced land surface. Kalyankar and Alaspurkar [2] proposed a data mining techniques to analyze Metrological data and to model the Weather forecasting system by taking the parameters such as temperature pressure and rainfall.

\subsection{Data assimilation}

The main objective of data assimilation provides production of initial conditions for operational forecasts. It also provides the construction of long term reanalyzes' of atmospheric state. Data assimilation is considered as one type of an analysis method where as information from the accumulation of observations over a period of time and converted into model state. There are three components in 
Data-assimilation process. Observations, Background information about atmosphere state based on model forecast, dynamic constraints forecast modeling. Ghil and Rizzoli have introduced in Data assimilation in meteorology and oceanography. Heintzen and Charlson are given detailed description about Weather forecasting System by using Cloud computing techniques [3]. Yadav and Khatri is proposed weather forecasting model using Data mining techniques [4]. Olaiya and Adeyemo have focused on different applications of weather prediction and Climate change studies by using Data mining Techniques [5]. Hemalatha is focused on the report of weather forecasting system for the implementation of Data Mining and Global Positioning Systems with the help of ID3 algorithm.

\section{Modeling for surface process of Weather forecasting}

Weather and climate -prediction models are represented by the movement of heat and water

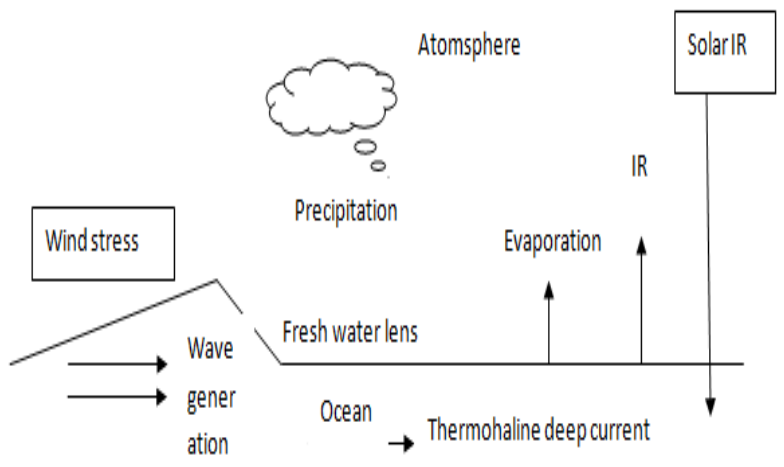

Fig. 1: Modeling for Surface Process of Weather Forecasting.

Within the plant canopy and the ground beneath. Seasonal Variation of Surface heating provides the difference between continents and oceans which gives monsoon circulations on larger scales. Vertical movement of heat at the atmosphere interface occurs through conduction process. It consists of a very shallow layer of atmosphere which is called the laminar sub layer. It is having a depth of few molecules to a few millimeters. Generally, forecasting of two or more week prepared with two variables such as water temperature, ice cover to the atmospheric-model simulation. The following figure shows the physical process with the movement of heat and mass in Ocean [1].

\subsection{Model initialization process}

Initialization of model is performed by taking two requirements One is dependent variables and second one is gridded mass field variables and momentum field variables. Two approaches are required for doing the initialization. One is called static initialization and second one is called dynamic initialization. In case of static initialization, the observations are interpolated to a model grid such as data analysis. Dynamic initialization involves the reforecast in tegration of the model to produce an initial state which is dynamically consistent with the equations for the forecast.

\subsection{Data assimilation}

Normally data assimilation is to be obtained by taking the combination of information from observations and Numerical methods. It should act as major role for the improvement of weather forecasts. Data assimilation provide mathematical framework from the resources independently. At the initial time of forecast Data assimilation and data analysis both are referred to the processes which employ observations for the construction of gridded datasets which consists of dependent variables at the initial time of a forecast. The main objective of data assimilation can be the creation of initial conditions for operational forecasts [6]

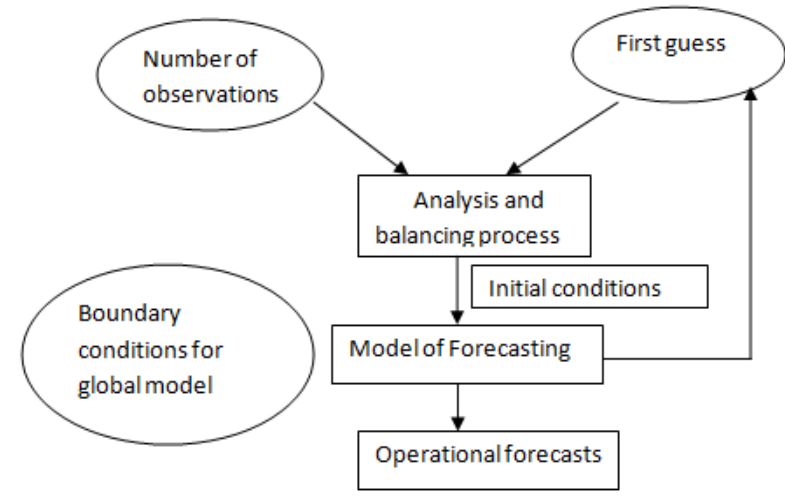

Fig. 2: The Process of Intermittent, Data Assimilation.

\section{Statistical framework for data assimilation}

State vectors ' $p$ ' may be defined on a model grid. Depending on the analysis, unknown and known back ground vector are represented as $\mathrm{pa}_{\mathrm{a}} \mathrm{p}$. It can define the values of a single variable in a two-dimensional space, $T_{b}(p, q)$. The vector length $n$ is the product of the number of variables and the number of grid points.

State and observation vectors are defined as follows

$\mathrm{p}_{\mathrm{t}}=$ True model state vector

$\mathrm{p}_{\mathrm{a}}=$ analysis model state vector

$\mathrm{p}_{\mathrm{f}}=$ forecast model state vector

$\mathrm{p}_{\mathrm{b}}=$ background model state vector

$\mathrm{q}=$ vector of observations.

Error covariance matrices are defined as follows

$\mathrm{B}$ is the covariance matrix of forecast errors. The dimensions of error matrix are nxn. It controls the function in terms of shape and magnitude. At an observation point information in the innovation vector is defined. It can be translated into B into a variable analysis increment at surrounding grid points to reduce the analysis error.

$B=\overline{\left(\varepsilon_{a}-\overline{\varepsilon_{b}}\right)^{2}}$

In a multi-dimensional system

$B=\overline{\left(\varepsilon_{a}-\overline{\varepsilon_{b}}\right)\left(\varepsilon_{a}-\overline{\varepsilon_{b}}\right)^{T}}$

Large-scale weather Philomena in a region into a specific number of different, dominant weather regimes, classes based on a variable such as sea-level pressure. The impact of Climate impacts must be forecast, understood and dealt with at local and regional levels. This need has motivated many of current and future climate downscaling activities. In current situation, it can be generalized that the atmospheric models are good tools for evaluating the historical changes on climate. [7].

\section{Cloud computing techniques for weather forecasting model}

Cloud computing is considered as one type of internet -based computing .It provides shared computer processing resources and data to computers and other devices on demand. It is a model for sharing computer resources based on demand. Cloud computing and storage solutions provide users and enterprises with various capabilities to store and process their data in either privately owned that may be located far from the user-ranging in distance from across a city to across the world. 


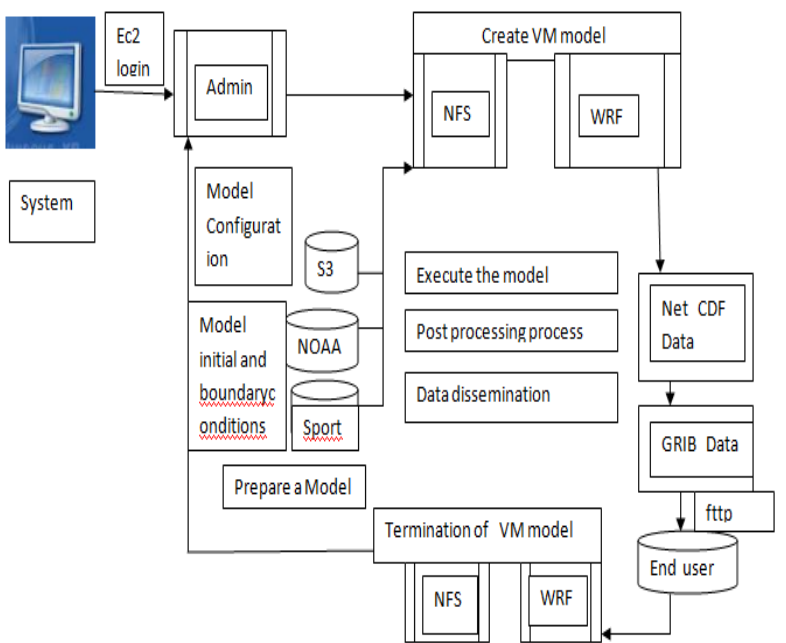

Fig. 3: Weather Forecasting Model by Using Cloud Computing Techniques [5].

Cloud computing techniques are suitable for meteorological applications. Cloud resources serves as the backbone to countless webpage and web driven applications are used by general public including data processing and distribution systems that disseminate key weather forecasting, severe weather warning, and climate information. We use cloud services to execute now casting algorithm for our Cloud cast application [5]. Cloud computing platforms lower than cost of computation by leveraging economies of scale. It reduces cost and energy and time.

\subsection{Implementation}

We present the results of live analysis performed with our own radar located on our campus. Calculate Now casting's cost and computation time for one hour of weather data for the simulation instance types offered by Amazon EC2.We bring up the instances with the Now casting image and start the ingest of weather data from the radars. Once the cloud based now cast instance receives the first set of radar scans, it starts to generate 1 to 15 minutes.

We carry out this operation for one hour of weather data and determine the cost for one hour. Now cast operation using cost tracking services provided by Amazon EC2.We can do liver measurement on each of four cloud instance for calculating overall time taken for now casting process. This process is suitable for cloud cast application on cloud services. Generation of data is performed by using radar.

Data is transmitted to a particular instance by the execution of algorithm within 15 minutes.

Now cast images are generated and are sent to a central web server which is used by client. Here Amazon EC2 is a cloud service that provides resizable compute capacity to execute applications on demand. EC2 provides on-demand resources with pricing depending on the type of resources used and duration of usage.

\section{Data mining techniques for weather predic- tion model}

\subsection{Data mining method}

In the data mining methods the following steps are follows; Data Collection, data selection, data transformation and Data mining methods are used [10].

a) Data cleaning

In this data model is prepared with consistent format by taking care of data missing. Cleaned data is more suitable for data mining.

b) Data selection

Data relevant to the analysis and meteorological dataset had 10 attributes.
Now a day's weather conditions are obtained by taking ground observations and observations are taken from ships and aircraft, radiosonde, Doppler radar, and satellites. This type of information is sent to various meteorological centers. In these centers, the data collection analyses on data operations are well performed. It is converted into in the form of variety of charts, maps, and graphs [9]. Modern high-speed computers transfer the many thousands of observations onto surface and upper-air maps. Computers draw the lines on the maps with help from meteorologists, who correct for any errors. A final map is called an analysis. Computers not only draw the maps but predict how the maps will look sometime in the future. The forecasting of weather is performed by using computer is known as numerical weather prediction. Weather prediction is performed by using numerical analysis. Atmospheric models are developed by using by using mathematical equations to provide description of atmospheric temperature, pressure and moisture will change over time. These equations are converted in the form of computer programming and data is present with atmospheric conditions which are fed into the computer. These equations are solved with the help of computer and show the equations to determine how the different atmospheric variables will change over the next few minutes. This procedure is repeated again and again using the output from one cycle as the input for the next cycle.

Climate change is considered as significant change in Statistical distributions of weather patterns with respective weather conditions [8]. Here data mining techniques are used for finding relevant information from huge quantity of data.

Table 1: Attributes of Meteorological Dataset

\begin{tabular}{|c|c|c|}
\hline Attribute & Type & Description \\
\hline Temperature & $\begin{array}{l}\text { Numerical } \\
\text { values }\end{array}$ & $\begin{array}{l}\text { Consider the } \\
\text { amount } \\
\text { temperature. }\end{array}$ \\
\hline Radiation & $\begin{array}{l}\text { Numerical } \\
\text { values }\end{array}$ & $\begin{array}{l}\text { The amount } \\
\text { of radiation }\end{array}$ \\
\hline form Cloud & $\begin{array}{l}\text { Numerical } \\
\text { values }\end{array}$ & $\begin{array}{lr}\text { The mean } \\
\text { amount } \\
\text { Cloud }\end{array}$ \\
\hline Rain & $\begin{array}{l}\text { Numerical } \\
\text { values }\end{array}$ & $\begin{array}{l}\text { Total } \\
\text { monthly } \\
\text { rainfall }\end{array}$ \\
\hline year & $\begin{array}{l}\text { Numerical } \\
\text { values }\end{array}$ & $\begin{array}{l}\text { Consider the } \\
\text { year }\end{array}$ \\
\hline Month & $\begin{array}{l}\text { Numerical } \\
\text { values }\end{array}$ & $\begin{array}{l}\text { Consider the } \\
\text { month }\end{array}$ \\
\hline
\end{tabular}

Forecasting the weather based on Rainfall, Temperature, Air quality for selected cities:

Analysis of numerical data values for Rainfall, Temperature and Air quality in select metros on $29^{\text {th }}$ March 2017 [11]. These values can be shown above figure.

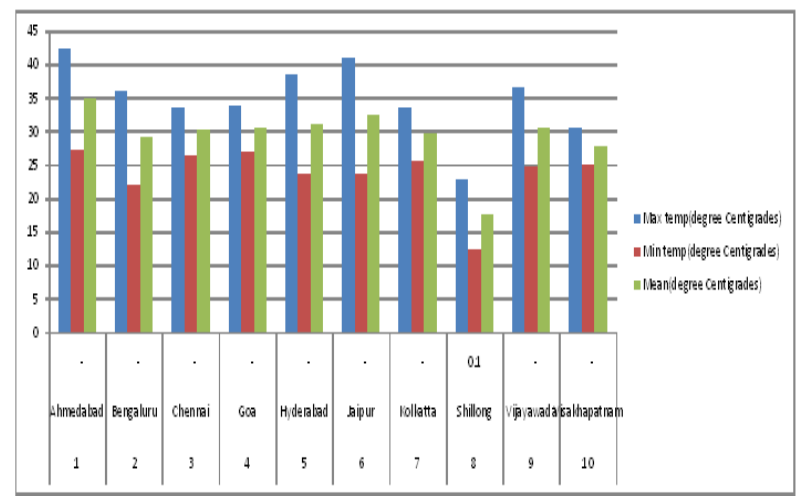

Graph 1: Analysis of Numerical Data Values for Rainfall, Temperature and Air Quality 
Table 2: Max \& Min Temperature Values for Various Cities

\begin{tabular}{|c|l|c|l|l|l|}
\hline S1.no & $\begin{array}{l}\text { Name of the } \\
\text { place }\end{array}$ & Rain & $\begin{array}{l}\text { Max } \\
\text { temp(degree } \\
\text { Centigrades) }\end{array}$ & $\begin{array}{l}\text { Min } \\
\text { temp(degree } \\
\text { Centigrades) }\end{array}$ & $\begin{array}{l}\text { Mean(degree } \\
\text { Centigrades) }\end{array}$ \\
\hline 1 & Ahmedabad & - & 42.40 & 27.20 & 34.8 \\
\hline 2 & Bengaluru & - & 36.02 & 22.00 & 29.01 \\
\hline 3 & Chennai & - & 33.61 & 26.42 & 30.15 \\
\hline 4 & Goa & - & 33.83 & 27.01 & 30.42 \\
\hline 5 & Hyderabad & - & 38.62 & 23.72 & 31.17 \\
\hline 6 & Jaipur & - & 41.01 & 23.64 & 32.325 \\
\hline 7 & Kolkatta & - & 33.64 & 25.61 & 29.625 \\
\hline 8 & Shillong & & 22.82 & 12.33 & 17.57 \\
\hline 9 & Vijayawada & - & 36.51 & 24.62 & 30.565 \\
\hline 10 & Visakhapatnam & - & 30.63 & 25.01 & 27.82 \\
\hline
\end{tabular}

Table 3: Numerical Dataset Values for Air Quality

\begin{tabular}{|l|c|c|c|c|c|c|}
\hline Cities & $\mathrm{SO2}$ & $\mathrm{NO2}$ & $\mathrm{CO}$ & $\mathrm{PM2.5}$ & $\mathrm{PM10}$ & $\mathrm{CODE}$ \\
\hline Ahmechabad & - & - & - & - & - & - \\
\hline Bengalun & 20.01 & 32.02 & 19.02 & 62.03 & & \\
\hline Chennai & 10.02 & 25.01 & 20.01 & 118.01 & & \\
\hline Delhi & 39.03 & 156.00 & 76.02 & 230.02 & 301.02 & \\
\hline Hyderabad & 31.02 & 37.02 & 32.03 & 101.01 & 124.03 & \\
\hline Kolkata & 7.01 & 18.03 & 43.04 & - & 53.04 & \\
\hline Luck now & 18.01 & 83.02 & 45.01 & 340.03 & - & \\
\hline Mumbai & 16.01 & 22.01 & 26.02 & 86.02 & 139.02 & \\
\hline Pune & 35.01 & 44.04 & 3.01 & 130.03 & 106.01 & \\
\hline Vishakhapatnam & - & - & 55.02 & - & - & - \\
\hline
\end{tabular}

Particular Matter In the Air You are Breathing

Air Quality

Good

Moderate

Poor

\section{Proposed algorithm}

Decision tree is built up with proposed algorithm with a following set of values.

Input: Set of attributes

Output: Weather prediction model

$\mathrm{A}:=\{\mathrm{A} 1 \ldots . . \mathrm{An}\}$ is the set of target attributes value.

\{

If $\mathrm{D}=\phi$

Then it returns anode with unsuccessful attribute value and produces a decision tree.

If ( $\mathrm{D}$ consists of number of records are having the same value for the target attribute values)

Then it returns a single node with that single value

If $\mathrm{C}=\phi$

Then it returns a single node with Successful attribute values are placed in number of records $\mathrm{Z}$.

Let us take the attribute values are ranging from $1 \ldots \ldots n$ for ri in $\mathrm{C}$. Let us take the subsets of $\mathrm{T}$ containing the values from $1 \ldots \ldots \ldots . \mathrm{K}$ for $\mathrm{Tj}$ consisting of record with dj of attribute $\mathrm{R}$

It Returns a tree with roots is labeled D and arcs are labeled $\mathrm{d} 1, \mathrm{~d} 2$ ...dm

Values are (C- $\{Z\}, A, T 1),(C-\{R\}, A, T 2) \ldots,(C-\{R\}, C, S m)$ End

$$
\text { \} }
$$

\subsection{Results and analysis}

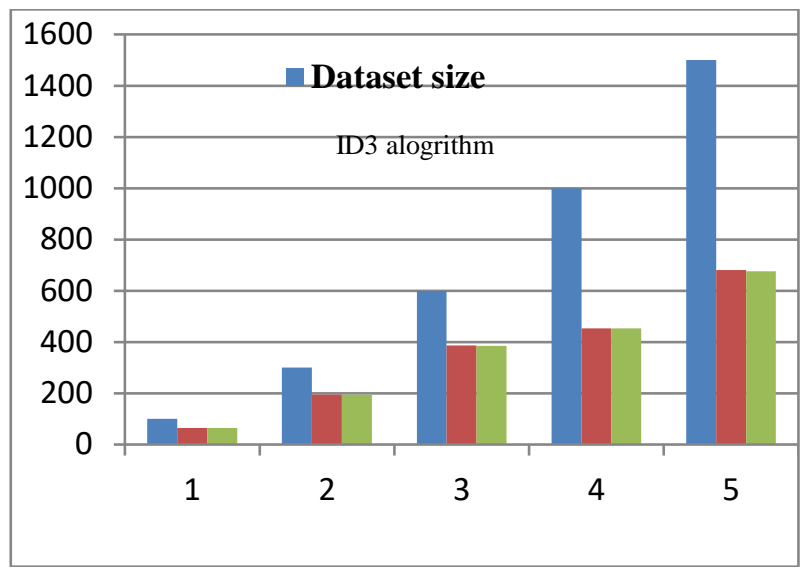

Fig. 4: Variation in between Proposed Algorithm and ID3 Algorithm.

The results and analysis about parameters have been shown the following figure.

\subsection{Decision tree}

Decision tree is constructed with this proposed algorithm. Set of records are having structure, attribute values. Usually Successful attributes are taken as true or false or failure, success.

Table 4: Attribute Name-Possible Values

\begin{tabular}{|l|l|}
\hline Attribute Name & Possible values \\
\hline Climate & $\begin{array}{l}\text { Sunny, Cloudy, } \\
\text { Rainy }\end{array}$ \\
\hline Temperature & Continuous \\
\hline Humidity & Continuous \\
\hline Stormy & True, False \\
\hline
\end{tabular}

\section{Constraint $\mathrm{s}$ for the construction of decision tree}

Weather prediction model is based on with respective weather conditions. The following values are taken which are present in the given table.

Constraints for the construction of decision tree using the above values.

Constraint 1: If the climate is Sunny then Stormy is true when Temperature \&\& Humidity is in the range of $40^{\circ} \mathrm{c}$ to $45^{0} \mathrm{c}$ then It is in safe state.

Constraint 2: If the climate is Cloudy then Stormy is False or True when

Temperature \&\& Humidity is in the range of $25^{0} \mathrm{c}$ to $35{ }^{0} \mathrm{c}$ then it is in Unsafe state.

Constraint 3: If the climate is Rainy then Stormy is True or false when

Temperature \&\& Humidity is in the range of $20^{\circ} \mathrm{c}$ to $30^{\circ} \mathrm{c}$ then it is in Safe state.

Table 5: Numerical Values for Decision Tree Construction

\begin{tabular}{|l|c|l|l|l|}
\hline Climate & $\begin{array}{l}\text { Temperature(degree } \\
\text { centigrade's) }\end{array}$ & $\begin{array}{l}\text { Humidity(grams } \\
\text { of water/mm }\end{array}$ & Stormy & State \\
\hline Sunny & 38 & 74 & T & Safe state \\
\hline Sunny & 25 & 80 & F & Unsafe state \\
\hline Sunny & 35 & 76 & T & Safe state \\
\hline Cloudy & 23 & 92 & F & Unsafe state \\
\hline Cloudy & 24 & 86 & T & Unsafe state \\
\hline Cloudy & 25 & 76 & F & Unsafe state \\
\hline Rainy & 26 & 70 & T & Safe state \\
\hline Rainy & 28 & 78 & T & Safe state \\
\hline Rainy & 25 & 65 & T & Safe state \\
\hline
\end{tabular}




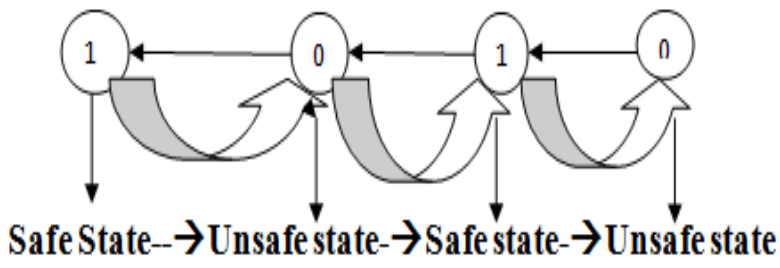

Fig. 5: State Chart Diagram for Climate Changes.

\section{Wind parameters}

Motion of air is called wind. It is expressed in terms of speed and direction. Wind is measured in terms of meters. Humidity, Rainfall, Wind speed, Wind direction, temperature condensation and water levels all these parameters are measured in terms of various sensors. Wind speed is low then the turbulence will be high. Higher the temperature and turbulence is also increased. Generation of turbulence is high by the temperature difference. Normally deviation of wind is $5^{0}$ to $10^{0}$ degrees.

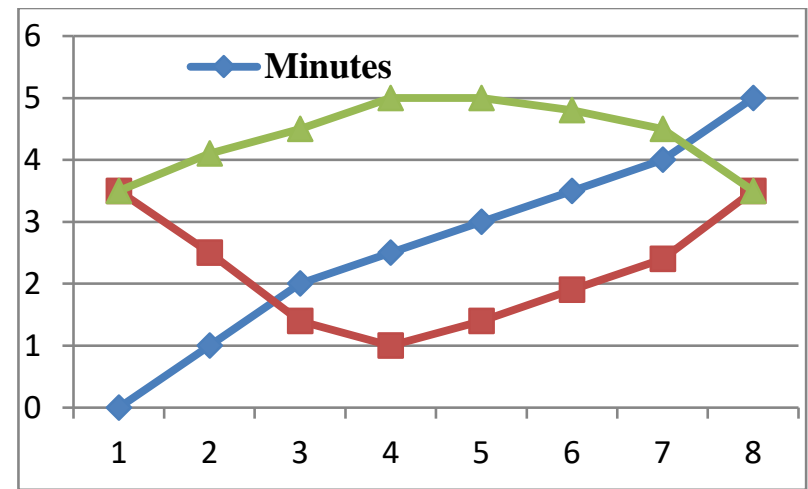

Fig. 6: Direction of Wind Speed with Respective Wind Speed, Wind Angle and Minutes.

\section{Conceptual level architecture of weather prediction model by using decision tree}

Conceptual level provides Formal way of the system. Here weather prediction model is designed with the conceptual architecture model by using decision tree. This process is easily understood by users. Here rounded rectangle is used for representing the concepts [12].

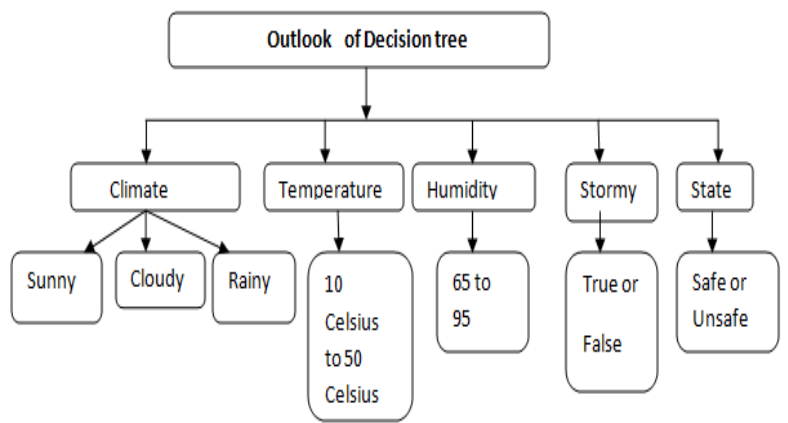

Fig. 7: Conceptual Level Architecture of Weather Prediction Model by Using Decision Tree.

First level: It shows Outlook of Decision tree.

Second level: It shows the Climate, Temperature, Humidity, Stormy, State parameters Fig.7: Conceptual level architecture of Weather prediction model for modeling Weather forecasting system.

Third level: Climate parameters: Sunny, Cloudy, Rainy, Temperature parameters: $40^{0} \mathrm{c}$ to $45^{0} \mathrm{c}$, Humidityparameters: $40 \mathrm{Va}$ pour $/ \mathrm{mm}^{3}$ to 45 Vapour $/ \mathrm{mm}^{3}$, Stormy: True or False

\section{Design pattern for weather forecasting system}

Design pattern provides the flow of Weather forecasting Model. Weather forecasting Model is an Abstract class. Numerical Weather prediction and Cloud based Architecture for Weather Forecasting system are subclasses of Weather forecasting system. Concrete classes are Mathematical Model and Cloud Model. In case of Mathematical Model, Mathematical operators are attributes and Derivative function is an operation. In case of Cloud Model data is an attribute and Data is stored by using an Amazon Ec2.

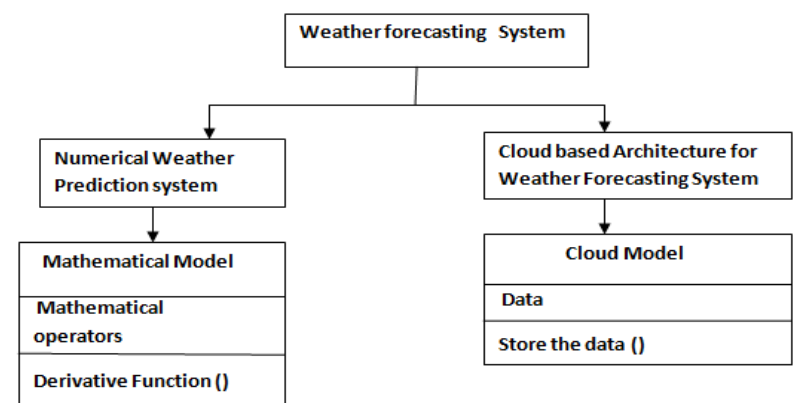

Fig. 8: Design Pattern for Weather Forecasting System.

\section{Implementation of weather report by using android material}

Mobile Application models are developed by J2ME and Android .It provides security and applications from uncorrected code. Java is well suited for an execution model of the system which is based on a virtual machine. Application permissions are not possible with J2ME. Consequently, read and write files are not running normally by using J2ME applications and arbitrary places are connected by open network connections. These are to be possible with Android. Mobile applications which are running by using J2ME and Android are made from assemblies of Java classes packaged into archives.

\subsection{Weather forecasting application by using android}

This process is implemented by considering three main areas. One is Toolbar area, second one is weather icon and temperature and third one is weather data.Weather forecasting model is developed by using current weather information. In this process the following parameters are used. Select various cities such as Bangalore, Chennai, and

Hyderabad. Choose one of the cities and display the temperature in Celsius. It also gives conditions of Weather.

\subsection{Result analysis}

Here weather application is considered as one type of real time application. Select one of the cities that can be given in first figure. Here I have taken various cities such as Bangalore, Chennai, and Hyderabad in the second figure. 


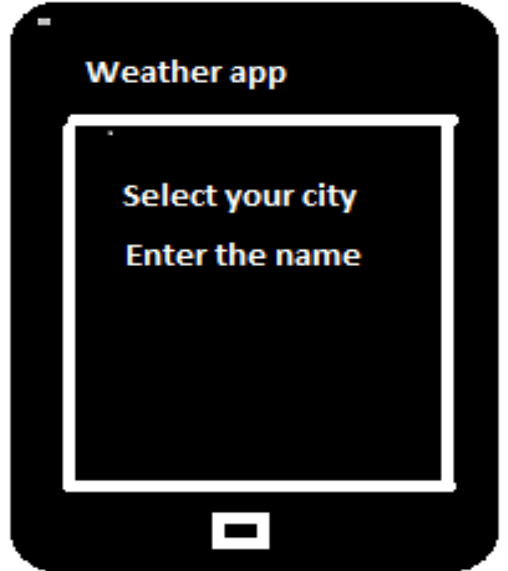

Fig. 9: A) Model of Weather Application.

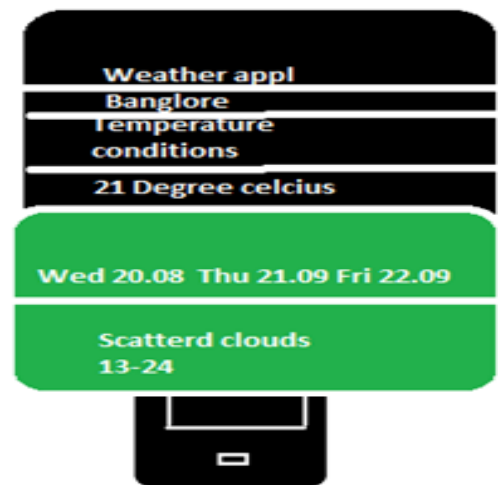

Fig. 9: B) Selection of Various Cities.

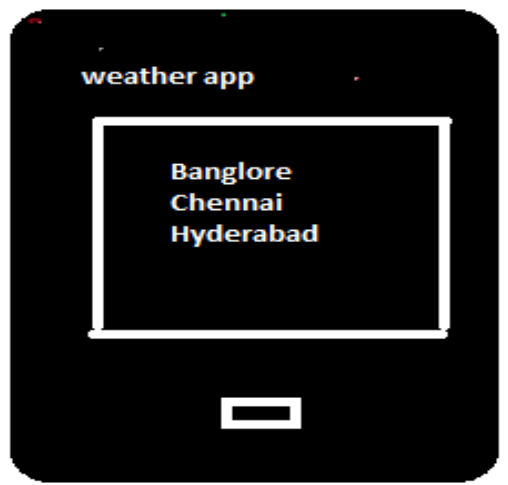

Fig. 10: Weather Conditions of Selected City.

The above screenshot shows Weather conditions such as temperature conditions for a particular city and also shown the cloud parameters.

\section{Conclusion}

This paper presents the study based on land surface model and provides heat fluxes with surface boundary conditions for Weather forecasting system. This paper also provides analysis for modeling of weather forecasting system with various techniques and Weather forecasting model by using Cloud computing techniques. The present paper mainly focused on the construction of decision tree with proposed algorithm.

\section{References}

[1] K.Rupakumar,A.K.Sahai,K.Krishnakumar,S.K.Patwardhan.etal'High resolution climate change scenarios for India for the $21^{\text {st }}$ century.Indian Institute of Tropical Meteorology,Pune411008,India.Currentscience ,Vol.90,NO.3,10 February 2006.

[2] MeghaliA.Kalyankar,Prof.S.J.Alaspurkar,"DataMining Technique to analyse the Metrological Data,International Journal of Advanced Research in Computer science and Software Engineering,Volume 3 Issue 2,February 2013.

[3] Chen.F and J.Dudhia Coupling an advanced land surface-hydrology model with Penn state-NCAR MM5 modeling System. Part I: Model implementation and sensitivity.Mon.Wea.Rev, 129, 569-585.

[4] Rohitkumaryadav, Ravi Khatri, "A Weather forecasting model using the DataMiningTechnique", International Journal of Computer Applications Volume 139-N0.14,April 2016.

[5] Fororunso Olaiya Application of Data mining Techniques in Weather Prediction and Climate Change Studies."International Journal of Information Engineering and Electronic Business 2012, 1, 5159. DOI:10.5815/ijieeb.2112.01.07.

[6] Ghil,M and P.PMalanotte-Rizzoli.Data assimilation in meteorology and oceanography.Adv.Geophys.,33,141-266.

[7] Glahn, B. Comments-Reforecast: An important data set for improving weatherpredictions.Bull.Amer.Meteor.Soc. 89, 1373-1378.

[8] HansonC.E., J.P.Palutikof,M.T.J.Livermore, etal.Modelling the impact of climate extremes: an overview of the MICE project. Climate change, 81, 163-177.

[9] Heintzenberg, J. andR.J.Charlson (2007).Clouds in the perturbed Climate System: Their relationship to energy balance, Atomspheric Dynamics and precipitation Cambridge,USA: MIT press.

[10] MeghaliA.Kalyankar,Prof.S.J.Alaspurkar,"DataMining Technique to analyse the Metrological Data,International Journal of Advanced Research in Computer science and Software Engineering,Volume3Issue2,February 2013.

[11] ChybickiA,Lubniewski.Z,Bruniecki.K,Markiewicz.L”Numerical weather prediction-Data fusion to GIS systems and potential applications,Croatian information technology association.-GIS Forum,university of Silesia,Zagerb 2011,56-61.

[12] S.L.Belousov,L.V.BerkovichandI.G.Sitnikov"Mathematical modeling in Meteorology and Weather forecasting "Mathematical models of life support system.

[13] P.Rajarajeswari,Dr.A.Ramamohanreddy,Dr.D.Vasumathi "Problem Solving Process Based on Conceptualmodel with Mathematical Techniques, "International Journal of Computer \& Mathematical Sciences ISSN 2347 - 8527 Volume 3, Issue 6 August 2014

[14] https://developer.android.com/index.html.

[15] Evans, J.P.21 ${ }^{\text {st }}$ century climate change in the Middle East. Climate Change, 92, 417, 432, doi: 10.1007/s10584-008-9438-5. 